\title{
Fiscaoeconomia
}

E-ISSN: 2564-7504

2021, Volume 5, Issue 3, 918-935

https://dergipark.org.tr/tr/pub/fsecon

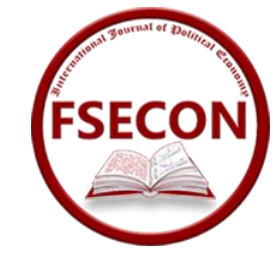

Research Article/Araştırma Makalesi

Submitted/Geliş: 22.06.2021

Accepted/Kabul: 20.08.2021

Doi: $10.25295 /$ fsecon.956217

\section{İnsan Kaynakları Uygulamalarının Algılanan Örgütsel Performansa Etkisi}

\author{
The Impact of Human Resources Practices on Perceived Organizational \\ Performance
}

\section{Belkıs KUZUTÜRK ${ }^{1}$, Erdem KIRKBEŞOĞLU², Şule TUZLUKAYA ${ }^{3}$}

\begin{abstract}
Öz
Günümüz rekabet koşulları göz önünde bulundurulduğunda insan kaynakları uygulamaları gerek akademik gerekse de uygulama açısından değerlendirilsin, örgütler için ayırt edici bir unsur olarak kabul görmektedir. Etkili insan kaynakları yönetim ve uygulamalarının örgüt performansına doğrudan olumlu katkıları bulunmaktadır. Insan kaynakları yönetimi, uyguladığı politikalar ve uygulamalar ile bireysel ve örgütsel hedeflerin başarımının eş zamanlı olmasında önemli rol üstlenmektedir. Geçen süreçte IKY uygulamalarını etkin bir şekilde sürdüren örgütler önemli kazanımlar elde etseler de birçok örgüt için tersine, kazanımlar istenilen düzeyde gerçekleşmemiştir. Aslında temel sorun IKY uygulamalarının içeriğiyle ilgili değildir. Özellikle kurumsallaşma düzeyi düşük birçok işletme yalnızca öykünmeci bir tavırla bu uygulamaları benimsemekte ve sonucu olarak performans artışı ve personel memnuniyeti sağlayamamaktadır. Diğer yandan kimi zaman performans artışı sağlayan birçok örgüt ise bunu başarısız IKY uygulamalarına rağmen sağlayabilmektedir. Bu nedenle çalışmamızda örgütsel performans kavramını karlılık veya verimlilik gibi somut çıktılar üzerinden değil çalışanların gözünden değerlendirmeyi amaçladık ve IKY uygulamalarının çalışan gözünden örgütsel performans üzerindeki etkisini sınadık. Elde edilen sonuçlar, insan kaynakları uygulamalarından işe alım, katılımcı karar alma, performans değerleme, ödüllendirme ve güçlendirme eylemlerinin örgütsel performans üzerinde anlamlı etkisi olduğu ortaya koyarken; uluslararası yazında etkisi olduğu kanıtlanan kurum içi eğitimler ve iş güvencesi değişkenlerinin herhangi anlamlı bir etki sağlamadığı sonucuna varılmıştır. Türkiye gibi çevresel belirsizliklerin yüksek olduğu bağlamlarda bu etkileşimin gerekçeleri yine bu çalışmada tartışımıştır.
\end{abstract}

Jel Kodları: O15, M1, L25.

Anahtar Kelimeler: Insan kaynakları uygulamaları, algılanan örgütsel performans, insan kaynakları yönetimi.

${ }^{1}$ belkiskuzuturk@gmail.com, ORCID : 0000-0002-2819-4535

2 Başkent Üniversitesi, Ticari Bilimler Fakültesi, erdemk@baskent.edu.tr, ORCID : 0000-0002-6781-9753

${ }^{3}$ Atılım Üniversitesi, İşletme Fakültesi, sule.tuzlukaya@atilim.edu.tr, ORCID : 0000-0001-8244-6396

Citation/Atıf: Kuzutürk, B.; Kırkbeşoğlu, E. \& Tuzlukaya, ş. (2021). Insan Kaynakları Uygulamalarının Algılanan Örgütsel Performansa Etkisi. Fiscaoeconomia, 5(3), 918-935. Doi: 10.25295/fsecon.956217 
Kuzutürk, B.; Kırkbeşoğlu, E. \& Tuzlukaya, Ş. (2021). İnsan Kaynakları Uygulamalarının Algılanan Örgütsel Performansa Etkisi. Fiscaoeconomia, 5(3), 918-935. Doi: 10.25295/fsecon.956217

\begin{abstract}
Considering today's competitive conditions, human resources practices are regarded as a distinctive factor for organizations, regardless of both academic and practical aspects. Effective human resources management (HRM) and practices have direct positive contributions to organizational performance. Human resources management plays an important role in synchronizing the policies and practices it implements and the achievement of individual and organizational goals. Although organizations that effectively continued their HRM practices in the past period achieved significant gains, for many organizations, on the contrary, the gains were not achieved at the desired level. In fact, the main problem is not related to the content of HRM practices. Especially many businesses with a low level of institutionalization adopt these applications only in an emulating manner and as a result, they cannot provide performance increase and personnel satisfaction. On the other hand, many organizations that sometimes increase performance can achieve this despite unsuccessful HRM practices. Therefore, in our study, we aimed to evaluate the concept of organizational performance from the perspective of employees, not through concrete outputs such as profitability or productivity, and we tested the effect of HRM practices on organizational performance from the perspective of the employee. The results show that recruitment, participatory decision making, performance evaluation, rewarding and empowerment actions from human resources practices have a significant effect on organizational performance; It was concluded that in-house trainings and job security variables proved to be effective in international literature do not provide any significant effect. the reasons for this interaction in the context of environmental uncertainty is high, such as Turkey was again discussed in this study.
\end{abstract}

Jel Codes: O15, M1, L25.

Keywords: Human resources applications, perceived organizational performance, human resources management.

\title{
1. Giriş
}

İnsan kaynakları uygulamaları örgütlerin rekabetçi iş ortamında rakiplerine stratejik üstünlük sağlamada kullanabilecekleri araçlardan bir tanesidir (Chiang vd., 2017; Horwitz, 2017). Örgütün bünyesinde bulunan en üst yöneticiden en alt düzeydeki iş görenlere kadar tüm çalışanları kapsadığı gibi, örgütün dışında bulunan ve potansiyel olarak yararlanılabilecek işgücünü de içermektedir. Insan kaynakları yönetimi (IKY) bir çalışma alanı olarak, erken dönem araştırmalarında sadece kayıt tutma ve idari personel işlerinden ibaret iken, günümüzde işletme stratejilerinin belirlenmesinde önemli rol oynayan bir konuma gelmiştir. Uzunca süredir literatürde sürdürülen çalışmalar, insan kaynakları yönetimi uygulamalarındaki gelişmelerin, işletme performansı üzerindeki olumlu etkilerini bulgulamaktadır (Keith \& Frese, 2011).

İnsan kaynakları uygulamaları çalışanı merkeze alarak, örgütün hedefleri doğrultusunda onları yönlendirip geliştirerek bireysel ve örgütsel performans artışına katkıda bulunmayı amaçlar (Huselid, 1995). Aynı zamanda, çalışanların bilgi, beceri ve yeteneklerinin geliştirilmesi ve örgüt ile bağlarının kuvvetlendirilmesi de sağlanmaktadır. Dolayısı ile insan kaynakları uygulamaları ve örgütsel performans arasındaki ilişkinin varlığından bahsetmek olanaklıdır. 
Kuzutürk, B.; Kırkbeşoğlu, E. \& Tuzlukaya, Ş. (2021). İnsan Kaynakları Uygulamalarının Algılanan Örgütsel Performansa Etkisi. Fiscaoeconomia, 5(3), 918-935. Doi: 10.25295/fsecon.956217

Yazında yer alan pek çok araştırmanın aksine, bu çalışma uygulamalar ve performans arasındaki ilişkiyi insan kaynakları yöneticileri üzerinden değil, çalışanların algısı üzerinden değerlendirmektedir. Örgütlerde üst düzey yöneticilerle gerçekleştirilen mülakatlarda, insan kaynakları uygulamalarının önemi bu yöneticiler tarafından sıklıkla vurgulansa da bunun hangi düzeyde etkin şekilde kullandığı sorgulandığında sonuçlar tersi yönde çıkabilmektedir. Daha açık bir ifadeyle yöneticiler, IKY uygulamalarının önemine inansalar da bunu başarılı bir şekilde uygulamak konusunda zayıf kalabilmektedirler. Dolayısıyla iş sistemlerinde kimi zaman bir moda etkisi şeklinde çıkan uygulamalar, örgütlerin veya yöneticilerin başka örgütlerdeki çeşitli uygulamalara öykünmesine neden olabilmektedir. Dolaysıyla yalnızca eşbiçimli olmak amacıyla benimsenen birçok uygulamanın sonuçları çoğu zaman başarı üretememektedir. Bu nedenle bu çalışmadaki amaç, İKY uygulamalarının örgüt performansına olan etkisini yöneticiler gözünden değil, o sürecin bir parçası olan çalışan gözünden değerlendirmektir.

\section{Algılanan Örgütsel Performans ve İKY Uygulamaları ile ilişskisi}

İnsan kaynakları uygulamalarında belirli standartların izlenmesi ve çalışanlara uygulanabilmesi aynı zamanda söz konusu uygulamaların çalışan tarafından algılanmasını da önemli hale getirmiştir (Hofman ve Meijerink, 2015). Yazında, algıladıkları performans düzeyi yüksek olan çalışanların genellikle anlık başarıları değil, uzun süreçlerdeki başarıyı hedef alan örgülerde görüldüğü ileri sürülmektedir (Varinli vd., 2009). Aynı zamanda, örgütün piyasa verimliliği ve müşteri memnuniyetini ele alan stratejik uzun vadeli planlar içinde olması, çalışanın algıladığı performansla da ilişkilidir (Varinli vd., 2009). Geçmişte çalışan algısı insan kaynakları uygulamaları tarafında göz ardı edilmiş olsa da çalışanlar tarafından olumlu algılanan eğitim, teşvik etme gibi uygulamaların varlığından bahsedilebilmektedir (Pombo \& Gomes, 2019). İnsan kaynakları yönetiminin göz ardı edemeyeceği önemli bir unsur olan performans algıSı, örgüt ve çalışan arasındaki ilişkiyi ileriye taşıyan değişkenler arasındadır.

Günümüzde insan kaynakları uygulamalarının stratejik önemi örgütlerde tartışmasız olarak giderek artmaktadır. Değişen koşullara uyumlu biçimde güncellenen insan kaynakları uygulamaları gerek bireysel çalışan performansının artması gerekse de örgütsel performansın gelişmesi anlamında önemlidir.

Insan kaynakları uygulamaları arasında yer alan adımlar örgütün faaliyetlerinin bütünsel olarak değerlendirilmesini, uygulamaların her başlı̆ı̆ın da sürece uygun şekilde ilerletilmesini içermektedir. Söz konusu uygulamalar seçici işe alım, eğitim, ücretlendirme, iş güvencesi, güçlendirme, çalışan katılımı, sembolik eşitlikçilik ve performans değerleme olarak ele alınmaktadır.

\section{1. Örgütsel Performans ve İşe Alım ilişkisi}

Bireyler rekabet üstünlüğü yaratma süreçlerinde örgütlere önemli avantajlar sunmaktadır (Wright vd., 2003). Tortop ve diğerleri (2006) seçici işe alma sürecinin, örgütün iş gücü ihtiyacının nicelik ve nitelik yönünden en iyi biçimde karşılanması adına iş gücü bulma eylemi olarak tanımlamaktadır. İ̧̧e alma, diğer bir ifade ile seçici işe alım, örgüt için maliyetli bir süreç olarak tarif edilebilir ve örgütler bu maliyeti en aza indirmek için belirli seçme sistemleri geliştirmektedir (Ergin, 2002). Örgüt stratejisinin ayrılamaz bir parçası olarak değerlendirilen seçici işe alım uygulamasını örgütler, göz ardı edemezler. Bu doğrultuda örgütler, hedefleri ile uyumlu, gerekli yetenek bilgi ve beceriyi temin etmelidir (Huselid ve Becker, 2010). Seçilen adayların örgüt kültürüne uyumu, öğrenime açık ve yeni fikirler geliştirebilen ayrıca 
Kuzutürk, B.; Kırkbeşoğlu, E. \& Tuzlukaya, Ş. (2021). İnsan Kaynakları Uygulamalarının Algılanan Örgütsel Performansa Etkisi. Fiscaoeconomia, 5(3), 918-935. Doi: 10.25295/fsecon.956217

denetimine az gerek duyulan kişiler olması örgütsel performans açısından önceliklidir. Örgütün çalışan politikasının olumlu ve sağlam temellere dayanabilmesi ancak ilkeli bir seçici iş gören temini politikasıyla mümkün olabilir ki; şeffat bir seçme süreci örgüte karşı güveni arttırdığı gibi daha verimli çalışmayı da sağlamaktadır (Sabuncuoğlu, 2000). Bu da örgütün yeteneğini etkileyerek örgüt hedeflerinin başarılmasında büyük rol oynar (Pfeffer, 1995) ve aslında seçici iş gören temini ile örgütler beşeri sermayesini oluştururken kendi örgütsel yeteneklerini de geliştirirler (Wang vd., 2007).

İşe alım ve seçme süreçlerinde, başvuru yapan kişiler aynı zamanda bir maliyet kalemi de (Scott vd., 1992) oluşturmakta, özellikle hatalı seçim durumlarında yeniden pozisyonu doldurma maliyeti önemli hale gelmektedir. Ayrıca seçim süreci uzadıkça boş olan pozisyonun diğer bireyler tarafından doldurulmaya çalışılması ya da üretim kaybı, seçme işine harcanan zaman vb. nedenler ile de maliyetler artmaktadır (Scott vd., 1992). Seçme faaliyeti yalnızca örgütün ihtiyacı duyduğu bilgi beceri ve yeteneğe sahip bireyleri işe alma süreci değil aynı zamanda bu bilgi beceri ve yeteneğe sahip bireyin de örgütü seçme sürecidir (Yüksel, 1997). Seçici işe alma, örgüt ve çalışanın biraraya gelme gayesini optimize ettiği nokta olarak da tarif edilebilir (Porter vd., 1975). Örgütler adaylar arasından seçecekleri çalışanı, örgüt kültürüne yakın (Beer \& Nathaniel, 2015), bilgisi ve becerisi ile eğitime açıklığı vb. özellikleri ile rekabet gücünü arttırıcı kişiler olarak seçmeye gayret ederler (Pfeffer, 1995). Bu aynı zamanda sürdürülebilir örgütsel performansın sağlanmasında da etkili olacaktır. Örgüt yöneticilerinde, örgütsel rekabet üstünlügünün seçim süreci ile gerçekleşeceği algısı oluştukça insan kaynakları uygulamaları ve performans arasındaki ilişki de öne çıkmaktadır. Bu şekilde değerlendirildiğinde ilk hipotezimiz aşağıdaki gibidir:

$H_{1}$ : Örgütlerde seçici işgören alımı uygulamalarının örgüt performansı üzerinde olumlu etkisi bulunmaktadır.

\section{2. Örgütsel Performans ve Eğitim iliş̧kisi}

Örgütler yaşayan sistemler olarak ekonomik, sosyal, teknolojik ve örgütsel değişim içindedirler (Sabuncuoğlu, 2000). Dolayısı ile, örgütün değişimine paralel olarak ilerleyecek sürekli yenilenme ve iyileşme yönünde adımların atılması, oryantasyon ve ardından da sürdürülebilir öğrenmenin desteklenmesi gerek bireysel gerekse de örgütsel hedeflerin gerçekleştirilmesi adına oldukça önemlidir. Yüksel (1997) özellikle değişen koşullara uyum sağlayacak biçimde çalışanların yetenek ve becerilerinin geliştirilmesinin önemine dikkati çekmektedir.

Bireylerin eğitim almasını sağlamak insan kaynakları yönetiminin bir parçasıdır ve yönetim; bilgiyi beceriyi ve kaynağı geliştirmek ve eğitimi sağlayarak insan kaynakları yönetimi stratejilerini desteklemektedir (Kağnıcıŏlu, 2001; Bayat, 2008).

Eğitimle soyut olan beşeri, entelektüel, sosyal sermaye gibi değerlere yapılan katkı taklidi zor iş gücü geliştirdiğinden örgütler için eşi bulunmaz bir rekabet avantajı kazandırmaktadır (Cheng \& Hampson, 2008). Doğru işe doğru çalışanın alınması ve çeşitli eğitim programlarının uygulanmasıyla çalışanların bilgi beceri ve yeteneklerini geliştirmek çalışanların işe ve örgüte bağlılı̆ını arttırır, motivasyonunu sağlar ve örgütün hedeflerine giden yolda insan sermayesinin en yüksek seviyede olmasını sağlayarak rekabet avantajını sürdürmesine, çalışma hayatının kalitesini arttırmayı sağlamaktadır (Bayat, 2008). Buna göre ikinci hipotezimiz aşağıdaki gibidir: 
Kuzutürk, B.; Kırkbeşoğlu, E. \& Tuzlukaya, Ş. (2021). İnsan Kaynakları Uygulamalarının Algılanan Örgütsel Performansa Etkisi. Fiscaoeconomia, 5(3), 918-935. Doi: 10.25295/fsecon.956217

$\mathrm{H}_{2}$ : Örgütlerde eğitim uygulamalarının, örgüt performansı üzerinde olumlu etkisi bulunmaktadır.

\section{3. Örgütsel Performans ve Ödüllendirme ilişkisi}

Örgütler, değer yaratan insan kaynağını ellerinde tutmak veya uzun dönemli istihdam sağlayabilmek amacıyla çeşitli ödüllendirme politikaları benimseyebilirler. Ücretlendirme, iş gücünü bireysel veya grup olarak örgüte katılan değerler için belirli şekillerde ve oranlarda ödüllendirilmesi ile gerçekleşmektedir (Pfeffer, 1995). İ̧̧ gücünü örgüte çekmek, örgütte tutabilmek ve motive edebilmek cazip bir ödüllendirme sistemi ile gerçekleşebilecektir (Yüksel, 1997). Örgütler düzgün bir sistemle uyguladıklarında ödüllendirme çalışanların daha yüksek seviyeden performans gösterdikleri ve işe karşı güdülendiklerini göstermektedir (Huselid, 1995).

$H_{3}$ : Örgütlerde ödüllendirme uygulamalarının örgüt performansı üzerinde olumlu etkisi bulunmaktadır.

\section{4. Örgütsel Performans ve iş Güvencesi ilişkisi}

Son yıllarda giderek önemi artan diğer bir insan kaynakları uygulaması da iş güvencesidir. Literatürde hatta kanunlarda bile çeşitli tanımları bulunmakla beraber genel anlamda iş güvencesi çalışanların işverenlerine karşı işlerinin korunmasıdır. İşverenlerin keyfi davranışlarını sınırlayarak, çalışanların haklarını koruyan piyasadaki kriz, durgunluk, değişen rekabet koşulları vs. belirsizliklerin doğurduğu olumsuzlukların çalışanlara karşı işlerini kaybetmeleriyle sonuçlanacak durumları ortadan kaldırmayı yönelik bir uygulamadır (Poyraz \& Kama, 2008). İ̧̧ güvencesi uygulamasında çalışan ve örgüt kendi çıkarları doğrultusunda uzun dönem beraberliklerine odaklanmaktadır (Pfeffer \& Veiga, 1999; Beer \& Nathaniel, 2015).

İş güvencesinin azalması çalışanda iş tatmini ve örgüte bağlılı̆ı azaltmaktadır (Poyraz \& Kama, 2008). Dolayısı ile, çalışanlara uzun dönem birliktelik garantisi sağlandığında çalışanların iş verimliliği artarak, örgüt kültürüne uyumlu ve örgüte bağlı insanların örgütte kalması sağlanabilmektedir (Beer \& Nathaniel, 2015). Çalışan devamlılı̆̆ının olması, yani çalışanların örgüt tarafından uzun süre çalışma garantisiyle örgütte kalacağını bilmesi, çalışanların eğitim ve geliştirme için daha istekli olmalarına da etki etmektedir (Pfeffer, 1995). Bu sayede, eğitim, gelişim ve çalışma bakımından daha istekli olabilecek ve iş verimi artabilecektir (Beer vd., 2009).

$H_{4}$ : İs güvencesi uygulamalarının örgüt performansı üzerinde olumlu etkisi bulunmaktadır.

\section{5. Örgütsel Performans ve Güçlendirme Ilişkisi}

Çalışan güçlendirme, yetki ve sorumluluk paylaşımı olarak ifade edilebilir (Quinn \& Spreitzer, 1997). Çalışan güçlendirme ile ilgili diğer düşünce ise tam tersi yönde risk alma, gelişme ve değişim olarak görülmekte ve sonucu olarak çalışanlarının eksikliklerinin tamamlayarak güvenilir ve güçlü çalışanlara sahip olma olarak değerlendirilmektedir (Doğan, 2006). Çalışan güçlendirme uygulamaları, çalışanın işi ile ilgili temel bilgi ve beceri düzeyinin üstüne çıkmasına yardımcı olan, aynı zamanda daha fazla gayret ve çaba göstermesine, yaratıcılığının ve enerjisinin de ortaya çıkmasına katkı verebilen bir uygulamadır (Doğan, 2006). Bu noktada, güçlendirilmiş çalışanın işini önemsemesi, süreci etkilemesi, düşüncelerini özgürce paylaşabilmesi benzeri sonuçları da gözlemlenebilmektedir (Doğan \& Demiral, 2009). 
Kuzutürk, B.; Kırkbeşoğlu, E. \& Tuzlukaya, Ş. (2021). İnsan Kaynakları Uygulamalarının Algılanan

Örgütsel Performansa Etkisi. Fiscaoeconomia, 5(3), 918-935. Doi: 10.25295/fsecon.956217

Örgüt çalışanlarının güçlendirme çalışmaları ile örgütün ürünleri ve müşterileri, üretim ve pazarlama süreçleriyle ilgili bütün bilgilere sahip olmaları çalışanların daha verimli olmalarını sağlamaktadır (Batt, 2002). Ayrıca çıkan ve çıkabilecek sorunlara anında müdahale etmelerini sağlayarak zamandan tasarruf edileceği gibi, örgütün imajına da olumlu katkıları olacaktır.

İşin süreciyle ilgili çalışanlar ne kadar bilgi sahibi olursa işin gelişmesi ve sorunların hiyerarşiye takılmadan hızlı bir şekilde yürümesine katkı sağlayabilmektedir. Özellikle çalışanlar için teknik bilgi, sorumluluk ve yetki ile güçlendirme gerekmektedir (Bailey vd., 2001). Güçlendirme çalışmaları çalışana verilen sorumluluk, yetki veya maddi olmayan diğer ödüllendirme süreçleri ile örgüte bağlıı̆̆ın arttırılması noktasında önemli katkıya sahiptir (Beer \& Nathaniel, 2015). Çalışanlar örgütlerinden maddi ödüllendirmenin dışında manevi destek ile de değerli olduklarını ve yetki ve sorumluluk verilerek örgütte önemli kararları aldıklarını hissetmek isterler (Stewart ve Brown, 2009). Dolayısıyla örgütte önemli olduğunu ve önemli işler yaptığını hisseden çalışan işini anlamlı bulur ve tüm süreçlere katılım gösterebilir (Gümüşlüoğlu \& Karakitapoğlu, 2010). Buna göre beşinci hipotezimiz aşağıdaki gibidir.

$H_{5}$ : Örgütlerin güçlendirme uygulamalarının örgüt performansı üzerinde olumlu etkisi bulunmaktadır.

\section{6. Örgütsel Performans ve Çalışan Katılımı iliş̧kisi}

Çalışan katılımı, kararların uygulayacak çalışanların katılımı ile alınması (Lowin 1968), yetki ve sorumlulukları dahilinde iş ile ilgili kararlara katılmasıdır (Park vd., 2010). Çalışanı katılımcı karar almaya yönlendirmek, yani yetkilendirmek gerekmektedir (Lawler, 1994). Çalışan yetkileri arttıkça, örgütü sahiplenme ve örgüte karşı sorumluluk duygusu ve örgüte duyulan güven ve bağlıı̆ı̆ da artması beklenmektedir (Ugboro \& Obeng, 2000; Tailby \& Winchester, 2005).

Rekabet üstünlüğü arayan ve bunu insan kaynağıyla gerçekleştirmek isteyen örgütler çalışanlarıyla ortak kararlar almalı ve onları da sürece dahil etmelidir (Iverson \& Zatzick, 2011). Çalışan katılımını destekleyen ve çalışanlarını güçlendiren örgüt yapıları daha etkin performansı yakalayabilecektir (Huselid, 1995). Çalışanların örgüt için karar verme ve sorun çözmede bizzat rol sahibi olması iş tatminini arttırır (Wood \& De Menezes, 2011). Çalışan ve yönetim arasındaki katılımcı karar vermenin getirdiği şeffaflık ve samimiyet yönetimin ve çalışanların belirttikleri fikirleri ve aldıkları kararları daha dikkatli uygulayarak işletmenin de performansını olumlu şekilde artmasını sağlayacaktır (Kutlu \& Duran, 2010). Dolayısı ile $\mathrm{H}_{6}$ aşağıdaki gibi oluşmaktadır:

$H_{6}$ : Çalışanların örgütte katılımcı karar almaları için geliştirilen uygulamaların, örgüt performansı üzerinde olumlu etkisi bulunmaktadır.

\section{7. Örgütsel Performans ve Performans Değerleme ilişskisi}

Performans değerleme örgütün hedefleri için planlama konusunda ve diğer insan kaynakları uygulamalarının sürdürülebilirliği için oldukça önemlidir. Çalışanları geliştirmek, örgütün beşeri sermayesini yukarılara çıkarmak, çalışanlara değer katmak ve kariyer yollarını çizmek açısından, ücretlendirme ve ödüllendirme ile ilgili politikalarda ve aynı zamanda örgütten ayrılması gereken çalışanların belirlemesi süreçlerinde hem nesnel hem de yasal bir uygulamadır (Bingöl, 2013). Performans değerlemenin temelinde performansı iyileştirmek 
Kuzutürk, B.; Kırkbeşoğlu, E. \& Tuzlukaya, Ş. (2021). İnsan Kaynakları Uygulamalarının Algılanan Örgütsel Performansa Etkisi. Fiscaoeconomia, 5(3), 918-935. Doi: 10.25295/fsecon.956217

yatmaktadır (Murphy \& Cleveland, 1995). Dolayısı ile, sonuç odaklı değil, çalışan tutum ve davranışlarını geliştirme odaklıdır (Youndt vd., 1996). Düzenli aralıklar ve sürdürülebilir bir düzende performans değerleme yapılan bir örgütte, örgütün ilerleyişi, güncel durumu ile geçmiş dönemlerin karşılaştırılması ve nispeten fikirler üretebilme imkanı doğmaktadır (Karcıoğlu \& Öztürk, 2009).

Örgütün rekabet avantajı sağladığı insanı değerlendirmesi son derece önemlidir çünkü bireysel performansların toplamı örgütün performansını belirlemektedir (Uyargil, 2013). Performans değerlemenin sonuçları insan kaynakları planlamasında ve insan kaynakları yönetimi kararlarında kullanılmaktadır. Performans değerleme sonucunda insan kaynakları yönetimine çalışanlarla ilgili örgütün hedeflerine giden yolda efektif davranışlar ve tutumlar gösterebilmeleri için ne yapmaları gerektiğine yönelik veriler sunulmakta, veriler sayesinde, çalışanların örgütsel amaçlar için ne kadar sorumluluk almaya teşvik edilmesi gerektiği ve yöneticilerin ellerindeki mevcut iş gücü ile neler yapabileceği öngörülebilir. Bireysel bazda çalışan performansının yükselmesi, örgütün stratejik hedeflerine ulaşmasında çok büyük rol oynamaktadır. Bu doğrultuda çalışmanın son hipotezi olan $\mathrm{H}_{7}$ aşağıdaki gibi oluşmaktadır:

$H_{7}$ : Örgütlerin performans değerleme uygulamalarının örgüt performans üzerinde olumlu etkisi bulunmaktadır.

Yukarıdaki hipotezlerimize bağlı kalarak çalışmamızın kavramsal çerçevesi aşağıdaki modelde ifade edilmiştir:

Şekil 1: Araştırmanın Modeli

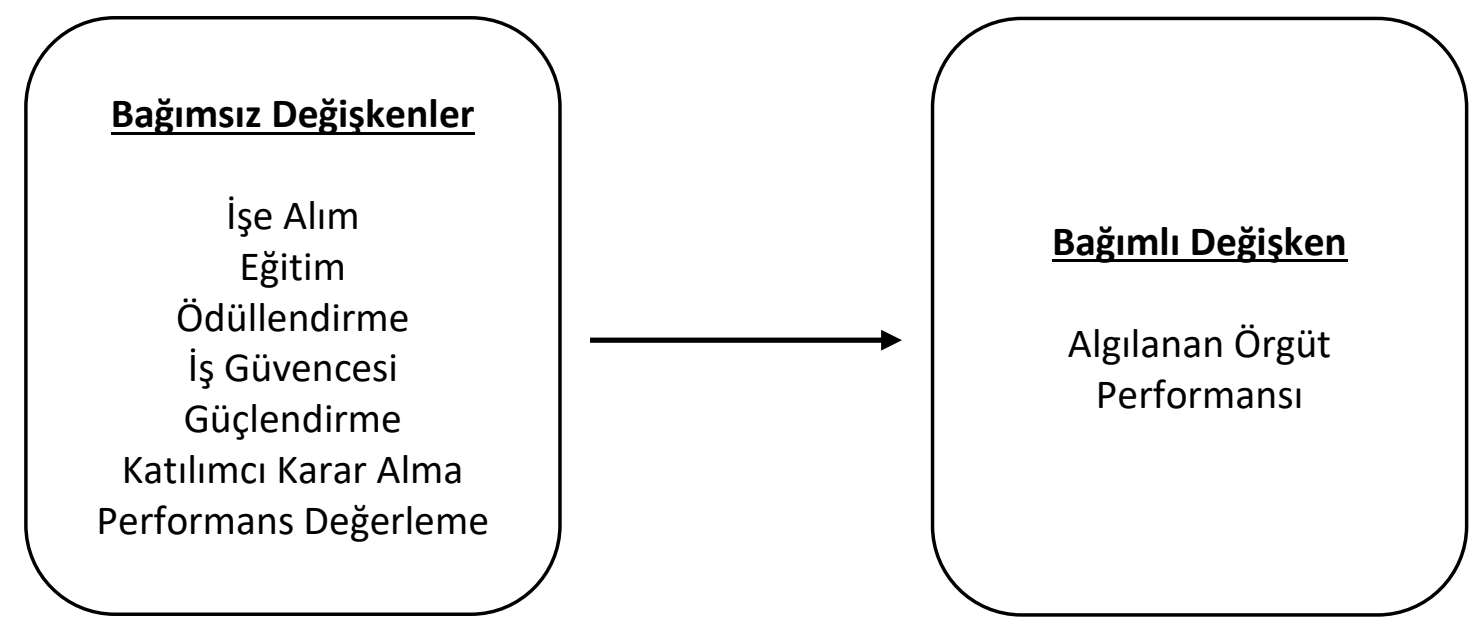

3. Analiz ve Bulgular

Araştırma hipotezlerini sınayabilmek adına veri toplama yöntemi olarak nicel araştırma yöntemlerinde sıklıkla kullanılan kesitsel tarama yöntemi tercih edilmiştir. Araştırmanın evrenini Türkiye genelinde tüm özel sektör çalışanları oluşturmaktadır. Türkiye genelinde 18 yaşından büyük, bordrolu özel sektör çalışanlarının bulunduğu e-posta veri tabanı üzerinden ulaşılan 78.811 kişiye ait e-posta aracılığı ile çalışanlara anketler ulaştırımıştır. Bu kapsamda çalışmada basit tesadüfi örnekleme yöntemi tercih edilmiştir. Eksiksiz doldurulan 324 anket örneklemi oluşturmuştur. Demografik özellikler incelendiğinde tüm kategorilerde nüfusun demografik dağılımına paralel bir dağılımın ortaya çıktığı ve örneklemin bu anlamda tutarlı olduğu sonucuna varılmıştır. 
Kuzutürk, B.; Kırkbeşoğlu, E. \& Tuzlukaya, Ş. (2021). Innsan Kaynakları Uygulamalarının Algılanan Örgütsel Performansa Etkisi. Fiscaoeconomia, 5(3), 918-935. Doi: 10.25295/fsecon.956217

Tablo 1: Veri Setine îlişkin Demografik Özellikler

\begin{tabular}{|c|c|c|c|c|c|c|c|}
\hline & & Sayı & Yüzde & & & Sayı & Yüzde \\
\hline \multirow{2}{*}{$\begin{array}{l}\text { Cinsiyete } \\
\text { Göre } \\
\text { Dağılımlar }\end{array}$} & Kadın & 195 & $60,2 \%$ & \multirow{18}{*}{ Sektör } & Bilişim & 23 & $7,1 \%$ \\
\hline & Erkek & 129 & $39,8 \%$ & & Eğitim & 40 & $12,3 \%$ \\
\hline \multirow{5}{*}{$\begin{array}{l}\text { Yaşa Göre } \\
\text { Dağılımlar }\end{array}$} & $18-29$ & 133 & $41,0 \%$ & & Finans & 30 & $9,3 \%$ \\
\hline & $30-39$ & 95 & $29,3 \%$ & & Güvenlik & 1 & $0,3 \%$ \\
\hline & $40-49$ & 49 & $15,1 \%$ & & Hukuk & 4 & $1,2 \%$ \\
\hline & $50-59$ & 32 & $9,9 \%$ & & İnsan Kaynakları & 7 & $2,2 \%$ \\
\hline & 60- & 15 & $4,6 \%$ & & Lojistijk & 3 & $0,9 \%$ \\
\hline \multirow{3}{*}{$\begin{array}{l}\text { Eğitim } \\
\text { Durumuna } \\
\text { Göre } \\
\text { Dağılımlar }\end{array}$} & \begin{tabular}{|l} 
ilk öğretim \\
veya lise
\end{tabular} & 39 & $12,0 \%$ & & Mağaza/Perakende & 11 & $3,4 \%$ \\
\hline & $\begin{array}{l}\text { Ön } \\
\text { lisans/lisans }\end{array}$ & 210 & $64,8 \%$ & & Otomotiv & 7 & $2,2 \%$ \\
\hline & Lisans üstü & 75 & $23,1 \%$ & & Reklamcılık & 10 & $3,1 \%$ \\
\hline \multirow{4}{*}{ İş Tecrübesi } & $0-1$ yıl & 80 & $24,7 \%$ & & Sağlık & 13 & $4,0 \%$ \\
\hline & $1-5$ yıl & 129 & $39,8 \%$ & & Sanayi & 11 & $3,4 \%$ \\
\hline & 6-9 yıl & 40 & $12,3 \%$ & & Tekstil & 6 & $1,9 \%$ \\
\hline & $10+y ı l$ & 75 & $23,1 \%$ & & Turizm/Gıda & 39 & $12,0 \%$ \\
\hline \multirow{4}{*}{$\begin{array}{l}\text { Pozisyona } \\
\text { Göre } \\
\text { Dağılımlar }\end{array}$} & Alt Kademe & 42 & $13,0 \%$ & & Üretim/Endüstriyel & 20 & $6,2 \%$ \\
\hline & Orta Kademe & 170 & $52,5 \%$ & & Yapı/Inşaat & 24 & $7,4 \%$ \\
\hline & Üst Kademe & 112 & $34,6 \%$ & & Diğer & 75 & $23,1 \%$ \\
\hline & & & & & TOPLAM & 324 & \\
\hline
\end{tabular}

Çalışmada bağımlı ve bağımsız değişkenler için kapsamlı bir literatür taraması gerçekleştirilmiş ve güvenirlik ve geçerlilik sorunu yaşamadığı bilenen ölçekler tercih edilmiştir. Bağımlı değişkenimizi oluşturan örgütsel performans değişkeni, iki alt ölçekle sınanmıştır. Literatürde örgütsel performansı ölçmede kullanılan, algılanan pazar performansı ve algılanan örgütsel performans ölçekleri birey düzeyinde örgüt performansının içsel bir perspektifle belirlenebilmesine imkân sağlar. Yedi soru algılanan örgütsel performans ve beş soru algılanan pazar performansı olmak üzere toplamda on iki sorudan oluşan bu ölçek Delaney ve Huselid'in (1996) geliştirdiği ölçektir. İşe alım düzeyi için Scott ve diğerlerinin (1992) ölçeğinden, iş güvencesi, ödüllendirme ve güçlendirme düzeyleri için Chin-Ju Tsai'nin (2006) ölçeklerinden, performans değerleme düzeyi için Guest ve diğerlerinin (2003) ölçeğinden, katılımcı karar alma düzeyi için ise Parnell ve Crandall'ın (2001) ölçeğinden faydalanılmıştır. Ölçekler İngilizceden Türkçeye tercüme edildikten sonra bir başka akran denetiminde yeniden İngilizceye çevrilmiş ve anlam bozuklukları olup olmadığı sınanmıştır.

Çalışmanın veri analizi SPSS programı yardımıyla gerçekleştirilmiştir. Veri analizi kısmında ilk olarak bağımlı ve bağımsız değişkenlerin içsel tutarlılıklarını görebilme adına güvenirlik analizi yapılmıştır. Güvenirlik analizi sonuçlarına göre $\alpha>0.70$ değeri esas alındığında tüm değişkenlerin yüksek güvenirlik içerdiği görülmektedir. Ayrıca yine Tablo 2'de ortalama ve standart sapma değerleri üzerinden örnekleme ilişkin dağılım betimlenmeye çalışılmıştır. 
Kuzutürk, B.; Kırkbeşoğlu, E. \& Tuzlukaya, Ş. (2021). İnsan Kaynakları Uygulamalarının Algılanan Örgütsel Performansa Etkisi. Fiscaoeconomia, 5(3), 918-935. Doi: 10.25295/fsecon.956217

Tablo 2: Araştırma Değişkenlerin Dağılımı ve Güvenirlik Düzeyleri

\begin{tabular}{|l|c|c|c|}
\hline Değişkenler & Ortalama & Standart Sapma & Cronbach Alfa \\
\hline İşe Alım & 3,67 & 1,01 & 0,83 \\
\hline Katılımcı Karar Alma & 4,37 & 0,69 & 0,82 \\
\hline İş Güvencesi & 3,38 & 1,08 & 0,85 \\
\hline Performans Değerleme & 3,58 & 1,09 & 0,85 \\
\hline Ödüllendirme & 3,37 & 1,16 & 0,91 \\
\hline Güçlendirme & 3,59 & 1,04 & 0,87 \\
\hline Örgütsel Performans & 3,68 & 0,76 & 0,94 \\
\hline
\end{tabular}

Bir sonraki aşamada, değişkenler arası karşılıklı etkileşimin istatistiksel olarak anlamlılı̆ını sınayabilmek adın korelasyon analizleri gerçekleştirilmiştir (bkz. Tablo 3). Gerçekleştirilen korelasyon analizlerinin sonucunda insan kaynakları uygulamalarına ait değişkenlerin kendi içerisinde önemli ölçüde yüksek korelasyon etkileşimine sahip oldukları görülmektedir. Demografik kontrol değişkenlerine ilişkin istatistiksel olarak anlamlı korelasyon etkileşimine ise sınırlı düzeyde ulaşılmıştır.

Tablo 3: Değişkenlerin Korelasyon Katsayıları ve Anlamlılıkları

\begin{tabular}{|c|c|c|c|c|c|c|c|c|c|c|c|}
\hline & Eğitim & Yaş & $\begin{array}{l}\text { Çalışma } \\
\text { süresi }\end{array}$ & Pozisyon & $\begin{array}{l}\text { İşe } \\
\text { Alım }\end{array}$ & $\begin{array}{l}\text { Katılımcı } \\
\text { Karar } \\
\text { Alma }\end{array}$ & $\begin{array}{l}\text { İş } \\
\text { Güven } \\
\text { cesi }\end{array}$ & $\begin{array}{l}\text { Performans } \\
\text { Değerleme }\end{array}$ & $\begin{array}{l}\text { Ödüllendir } \\
\text { me }\end{array}$ & $\begin{array}{l}\text { Güçlen } \\
\text { dirme }\end{array}$ & $\begin{array}{l}\text { Örgütsel } \\
\text { Performans }\end{array}$ \\
\hline \multicolumn{12}{|l|}{ Eğitim } \\
\hline Yaş &,- 038 & & & & & & & & & & \\
\hline Çalışma süresi &,- 058 &, $671^{* *}$ & & & & & & & & & \\
\hline Pozisyon & 059 &, $485^{* *}$ &, $531^{* *}$ & & & & & & & & \\
\hline İşe Alım & ,043 & , 079 & ,010 &, $203^{* *}$ & & & & & & & \\
\hline $\begin{array}{l}\text { Katılımcı Karar } \\
\text { Alma }\end{array}$ &, $141^{*}$ &,- 037 &,- 065 & ,042 & , 277** & & & & & & \\
\hline İş Güvencesi & ,006 &,- 028 &,- 033 & ,056 &, $483^{* *}$ &, $156^{* *}$ & & & & & \\
\hline $\begin{array}{l}\text { Performans } \\
\text { Değerleme }\end{array}$ & ,003 & ,035 &,- 016 & ,142* & ,656* &, $216^{* *}$ &, $446^{* *}$ & & & & \\
\hline Ödüllendirme &,- 022 & ,083 & ,022 &, $194^{* *}$ & ,619** &, $260^{* *}$ &, $489^{* *}$ & , $711^{* *}$ & & & \\
\hline Güçlendirme & 020 & 088 & ,023 &, $292^{* *}$ &, $588^{* *}$ & $168^{* *}$ &, $488^{* *}$ &, $540^{* *}$ &, $655^{* *}$ & & \\
\hline $\begin{array}{l}\text { Örgütsel } \\
\text { Performans }\end{array}$ &,- 060 &,- 004 &,- 087 & ,077 & ,651* & 096 &, $460^{* *}$ & ,649** &, $663^{* *}$ &, $591^{* *}$ & \\
\hline
\end{tabular}

*. Korelasyon 0.05 düzeyinde anlamlı.

**. Korelasyon 0.01 düzeyinde anlamlı.

Çalışmanın son aşamasında ise hipotezlerin sınanması adına regresyon analizi gerçekleştirilmiştir. Çalışma modelinde de değinildiği üzere IKY uygulamalarının örgütsel performans düzeyi üzerinde istatistiksel olarak anlamlı bir etkisi olduğu düşünülmektedir. Bu kapsamda regresyon analizi, hipotezlerimizin doğrulanıp doğrulanmadığına ilişkin sonuçlar üretecektir. Model 1, kontrol değişkenlerinin örgütsel performans üzerindeki açıklayıcılı̆̆ını ifade etmektedir. Model 2, IKY uygulamalarına ilişkin bağımsız değişkenlerin örgütsel 
Kuzutürk, B.; Kırkbeşoğlu, E. \& Tuzlukaya, Ş. (2021). İnsan Kaynakları Uygulamalarının Algılanan Örgütsel Performansa Etkisi. Fiscaoeconomia, 5(3), 918-935. Doi: 10.25295/fsecon.956217

performans üzerindeki açıklayıcılığını sınamaktadır. Son olarak model 3 ise, kontrol ve bağımsız değişkenlerin örgütsel performans değişkeni üzerindeki etkisini ifade etmektedir. íkY uygulamalarından bağımsız düşündüğümüzde demografik değişkenlerden çalışma süresi ve pozisyonun örgütsel performans üzerinde istatistiksel olarak anlamlı bir etkisi olduğu tespit edilmiştir. Ancak kontrol değişkenleri kapsam dışı bırakıldığında (model 2) veya dahil edildiğinde (model 3 ) işe alım, katılımcı karar alma, performans değerleme, ödüllendirme ve güçlendirme değişkenlerinin örgütsel performans üzerinde istatistiksel olarak anlamlı bir etki sağladığı tespit edilmiştir. Dolayısıyla $\mathrm{H1}, \mathrm{H3}, \mathrm{H} 5, \mathrm{H} 6$ ve $\mathrm{H} 7$ hipotezlerimiz doğrulanmıştır. Kurum içi eğitim ve iş güvencesi değişkenlerinin ise $(\mathrm{H} 2$ ve $\mathrm{H} 4)$ beklentinin tersine örgüt performansı üzerinde anlamlı bir etkisinin olmadığı sonucuna varılmıştır. Kurum içi eğitimlerin örgütsel performans üzerindeki etkisinin anlamsız çıkmasına temel gerekçe olarak; çalışanların ilgileri dışındaki eğitimlere zorlanmaları, iş yoğunluğu nedeniyle eğitime düzenli dahil olamamaları, ileri yaş grubunda eğitim olgusunun değer kaybedebiliyor olması ve işletmelerin eğitim konularının seçiminde kimi zaman odak dışındaki konulara yöneliyor olmaları gösterilebilir. Bu gibi sebepler nedeniyle kurum içi eğitimlerin istenen sonuca ulaşmayı zorlaştırdığı ve çalışanlar tarafından performansa yönelik katkısının zayıfladığı yorumu yapılabilir. İş güvencesinin örgütsel performans üzerindeki etkisinin anlamsız çıkmasına temel gerekçe olarak; çalışmanın ekonomik kriz döneminde gerçekleştirilmesi gösterilebilir. Özellikle ekonomik ve toplumsal krizlerin yüksek olduğu bağlamlarda, işletmeler her ne kadar yüksek iş güvencesi sunsalar dahi çalışanların kendilerini güvensiz hissetmeleri muhtemel olmaktadır. Dolayısıyla yüksek iş güvencesinde dahi örgütsel performansa etki edecek kadar bir etkileşimin olmayabileceği düşünülmelidir. Belirsizliğin düşük olduğu bağlamlarda iş güvencesinin performans üzerinde anlamlı bir açıklayıcılığı varken; Türkiye gibi belirsizliğin yüksek olduğu bağlamlarda bu etkileşimi yakalayabilmek zor olabilmektedir. Bu kapsamda literatürün tersine bu iki bağımsız değişkenin örgütsel performans üzerinde bir etkisinin olmadığı tespit edilmiştir.

Tablo 4: Regresyon Analizi Sonuçları

\begin{tabular}{|c|c|c|c|c|c|c|}
\hline \multirow[b]{2}{*}{ Bağımsız Değişkenler } & \multicolumn{2}{|c|}{$\begin{array}{c}\text { Model } 1 \\
\begin{array}{c}\text { Standardize Edilmiş Kat } \\
\text { Sayılar }\end{array} \\
\end{array}$} & \multicolumn{2}{|c|}{$\begin{array}{c}\text { Model } 2 \\
\begin{array}{c}\text { Standardize Edilmiş Kat } \\
\text { Sayılar }\end{array} \\
\end{array}$} & \multicolumn{2}{|c|}{$\begin{array}{c}\text { Model } 3 \\
\text { Standardize Edilmiş Kat } \\
\text { Sayılar }\end{array}$} \\
\hline & $\begin{array}{c}\text { Standart } \\
\text { Hata }\end{array}$ & Beta & $\begin{array}{c}\text { Standart } \\
\text { Hata }\end{array}$ & Beta & $\begin{array}{c}\text { Standart } \\
\text { Hata }\end{array}$ & Beta \\
\hline Yaş & 0,049 & 0,06 & & & 0,032 & 0,009 \\
\hline Çalışma Süresi & 0,055 & $-0,223 * * *$ & & & 0,036 & $-0,077$ \\
\hline Pozisyon & 0,077 & $0,171 * * *$ & & & 0,053 & $-0,065$ \\
\hline Eğitim & 0,072 & $-0,081$ & & & 0,047 & $-0,055$ \\
\hline İşe Alım & & & 0,04 &, $283 * * *$ & 0,04 &, $295 * * *$ \\
\hline Katılımcı Karar Alma & & & 0,041 &,$- 126 * * *$ & 0,041 &,$- 124 * * *$ \\
\hline İş Güvencesi & & & 0,031 & 0,059 & 0,031 & 0,046 \\
\hline Performans Değerleme & & & 0,039 &, $211 * * *$ & 0,039 &, $203 * * *$ \\
\hline Ödüllendirme & & & 0,039 &, $205^{* * *}$ & 0,038 &, $251 * * *$ \\
\hline Güçlendirme & & & 0,037 & $139 * * *$ & 0,038 &, $163 * * *$ \\
\hline
\end{tabular}

Bağımlı Değişken: Örgütsel Performans

*** \%99 güven düzeyinde anlamlıdır. 
Kuzutürk, B.; Kırkbeşoğlu, E. \& Tuzlukaya, Ş. (2021). İnsan Kaynakları Uygulamalarının Algılanan

Örgütsel Performansa Etkisi. Fiscaoeconomia, 5(3), 918-935. Doi: 10.25295/fsecon.956217

\section{Sonuç ve Öneriler}

İnsan kaynaklarının ortaya çıkışı, değişen çevre ve üretim faktörlerine karşın insan unsurunun rekabette belirleyici olacağı fikrine dayanmaktadır. Rekabet üstünlüğüne sahip örgütlerin pek çoğu insan kaynakları uygulamalarından yüksek düzeyde faydalanmış ve örgüt stratejisi ile birleştirmiştir. Geçen süreçte IKKY uygulamalarını etkin bir şekilde sürdüren örgütler önemli kazanımlar elde etseler de birçok örgüt için tersine, kazanımlar istenilen düzeyde gerçekleşmemiştir. Aslında temel sorun IKY uygulamalarının içeriğiyle ilgili değildir. Özellikle kurumsallaşma düzeyi düşük birçok işletme yalnızca öykünmeci bir tavırla bu uygulamaları benimsemekte ve sonucu olarak performans artışı ve personel memnuniyeti sağlayamamaktadır. Diğer yandan kimi zaman performans artışı sağlayan birçok örgüt ise bunu başarısız IKY uygulamalarına rağmen sağlayabilmektedir. Bu nedenle çalışmamızda örgütsel performans kavramını karlılık veya verimlilik gibi somut çıktılar üzerinden değil çalışanların gözünden değerlendirmeyi amaçladık.

Geçmiş dönemde Türkiye bağlamında gerçekleştirilen insan kaynakları yönetimi uygulamalarına dair araştırmalarda örgütsel performansı sıklıkla örgüt düzeyinden ve somut verilerle değerlendirilmiştir. Ancak örgütlerin yüksek performansa sahip olmalarına rağmen mevcut IKY uygulamalarının çalışan gözünden performansa olan yansıması göz ardı edilmiştir. Gelişmiş toplumlarda yürütülen IKY çalışmaları da benzer şekilde performansı somut ikincil veriler ile ölçmektedir. Ancak Türkiye gibi belirsizliğin yüksek olduğu bağlamlarda örgüt performansının ikincil veriler yoluyla değerlendirilmesi tek başına yeterli değildir. Devlete bağımlı bir iş sistemi yapısına sahip Türkiye örneği, İKY uygulamalarından haberi olmayan çok sayıda işletmenin yüksek satış hacimlerine veya karlılığa sahip olabildiği bir bağlamı temsil eder. Türkiye örneği bu anlamda örgütler arası ilişkilerin siyasi içerikli sosyal sermaye unsuruna yüksek düzeyde bağlı olduğu bir örnektir (Buğra, 1998). Bu nedenle çalışmamızda özgün olarak performans kavramını çalışan gözünden değerlendirmeye çalıştık.

IKY uygularına ilişkin bir diğer sorunlu unsur; bu uygulamaların birçok örgütte verimlilikten uzak bir algıyla sürdürülüyor olmasıdır. Örgütlerin öykünmeci eylemleri kimi zaman birbirlerinden bazı örnek uygulamaları transfer etmelerine veya model almalarına neden olur. Insan kaynakları yönetimi de birçok işletmede etkin bir şekilde sürdürülürken; özellikle küçük ve orta büyüklükteki işletmelerin bir kısmında olması gereken şekilde uygulanmamaktadır. Bu nedenle çalışma sonuçlarımız, personel gözünden örgüt performansına IKY uygulamalarının ne denli anlamlı etki sağlandığını göstermektedir.

Elde edilen sonuçlar, insan kaynakları uygulamalarından işe alım, katılımcı karar alma, performans değerleme, ödüllendirme ve güçlendirme eylemlerinin örgütsel performans üzerinde anlamlı etkisi olduğu ortaya koyarken; uluslararası yazında etkisi olduğu kanıtlanan kurum içi eğitimler ve iş güvencesi değişkenlerinin herhangi anlamlı bir etki sağlamadığı sonucuna varımıştır. Özellikle Türkiye bağlamında, çalışanların ilgileri dışındaki eğitimlere zorlanmaları, iş yoğunluğu nedeniyle eğitime düzenli dahil olamamaları, ileri yaş grubunda eğitim olgusunun değer kaybedebiliyor olması ve işletmelerin eğitim konularının seçiminde kimi zaman odak dışındaki konulara yöneliyor olmaları kurum içi eğitimlerin anlamsız etkisine gerekçe gösterilebilir. Diğer yandan özellikle ekonomik ve toplumsal krizlerin yüksek olduğu bağlamlarda, işletmeler her ne kadar yüksek iş güvencesi sunsalar dahi çalışanların kendilerini güvensiz hissetmeleri muhtemel olabilmektedir. Dolayısıyla belirsizliğin düşük olduğu 
Kuzutürk, B.; Kırkbeşoğlu, E. \& Tuzlukaya, Ş. (2021). İnsan Kaynakları Uygulamalarının Algılanan Örgütsel Performansa Etkisi. Fiscaoeconomia, 5(3), 918-935. Doi: 10.25295/fsecon.956217

bağlamlarda iş güvencesinin performans üzerinde anlamlı bir açıklayıcılığı varken; Türkiye gibi belirsizliğin yüksek olduğu bağlamlarda bu etkileşimi yakalayabilmek zor olabilmektedir.

\section{5. Çalışmanın Sınırılıkları}

Bu araştırma her araştırmada olduğu gibi bazı kısıtları bünyesinde barındırmaktadır. Çalışma örnekleminin basit tesadüfi örneklem tekniğiyle belirlenmesi sebebiyle değişkenler arası ilişkilerin anlamlılığı etkilenebilmektedir. Her ne kadar hipotezlerimiz önemli ölçüde doğrulanmışsa da doğrulanmayan hipotezler için bu handikap geçerli olabilir. Daha geniş bir örneklem ile bulgularda iyileşme beklenebilir.

\section{Kaynakça}

Bailey, T., Berg, P., \& Sandy, C. (2001). The Effect Of High-Performance Work Practices On Employee Earnings in The Steel, Apparel, And Medical Electronics And Imaging Industries. Industrial And Labor Relations Review, Cilt: 54, Sayı: 2A, ss. 525-543.

Batt, R. (2002). Managing Customer Services: Human Resource Practices, Quit Rates, And Sales Growth. Academy Of Management Journal, Cilt: 45 Sayı: 3, ss. 587-597.

Bayat, B. (2008). Insan Kaynakları Yönetiminin Stratejik Niteliği. Iktisadi Ve Idari Bilimler Fakültesi Dergisi, Cilt: 10, Sayı: 3, ss. 1-25.

Beer, M., Eisenstat, R., \& Foote, N. (2009). High Commitment High Performance: How To Build A Resilient Organization For Sustained Advantage. USA: John Wiley \& Sons.

Beer, M. R., \& Nathaniel, A. (2015). Human Resource System. High Commitment High Performance (S. 255-258). İçinde The United States Of America: Jossey- Bass.

Bingöl, D. (2013). Insan Kaynakları Yönetimi. Ankara: Beta.

Buğra, A. (1998). Non-Market Mechanisms of Market Formation: The Development of the Consumer Durables Industry in Turkey. New Perspectives on Turkey, 19, 1-28. doi:10.1017/S0896634600003009

Cheng, E., \& Hampson, I. (2008). Transfer Of Training: A Review And New Insights. International Journal Of Management Reviews, Cilt: 10, Sayı: 4, ss. 327-341.

Chiang, C. F., \& Liu, B. Z. (2017). Examining job stress and burnout of hotel room attendants: internal marketing and organizational commitment as moderators. Journal of Human Resources in Hospitality \& Tourism, Cilt: 16, Sayı: 4, ss. 367-383.

Chin-Ju, T. (2006). High Performance Work Systems And Organizational Performance: An Emprical Study Of Taiwan's Semiconduductor Desing Firms. The International Journal Of Human Resource Management, Cilt: 17, Sayı: 9, ss. 1512-1530.

Delaney, J. T., \& Huselid, M. A. (1996). The impact of human resource management practices on perceptions of organizational performance. Academy of Management journal, Cilt: 39, Sayı: 4, ss. 949-969.

Doğan, S. (2006). Personel Güçlendirme. Ankara: Kare Yayınları. 
Kuzutürk, B.; Kırkbeşoğlu, E. \& Tuzlukaya, Ş. (2021). İnsan Kaynakları Uygulamalarının Algılanan Örgütsel Performansa Etkisi. Fiscaoeconomia, 5(3), 918-935. Doi: 10.25295/fsecon.956217

Doğan, S., \& Demiral, Ö. (2009). Örgütsel Bağlılı̆̆ın Sağlanmasında Personel Güçlendirme Ve Psikolojik Sözleşmenin Etkisine İlişkin Bir Araştırma. Erciyes Üniversitesi Iktisadi Ve Idari Bilimler Fakültesi Dergisi, Cilt: 32, Sayı: 1, ss. 47-80.

Ergin, C. (2002). Insan Kaynakları Yönetimi ' Psikoılojik Bir Yaklaşım'. Ankara: Academyplus Publishing.

Guest, E., Michie, J., Conway, N., \& Sheehan, M. (2003). Human Resource Management And Corporate Performance In The UK. British Journal Of Industrial Relations, Cilt: 41, Sayı: 2, ss. 291-314.

Gümüşlüoğlu, L., \& Karakitapoğlu, A. (2010). Bilgi Çalışanlarının Adalet Ve Güçlendirme Algılarının Örgüte, Lidere Ve İşe Bağııık Üzerindeki Etkileri. Türk Psikoloji Dergisi, Cilt: 25, Sayı: 66, ss. 21-36.

Hofman, E., \& Meijerink, J. (2015). Platform thinking for services: The case of human resources. The Service Industries Journal, Cilt: 35, Sayı: 3, ss. 115-132.

Horwitz, F. (2017). International HRM in South African multinational companies. Journal of International Management, Cilt: 23, Sayı: 2, ss. 208-222.

Huselid, M. (1995). The Impact Of Human Resource Management Practices On Turnover, Productivity, And Corporate Financial Performance. Academy Of Management Journal, Cilt: 38, Sayı: 3, ss. 635-672.

Huselid, M., ve Becker, B. (2010). Bridging Micro And Macro Domains: Workforce Differentiation And Strategic Human Resource Management. Journal Of Management, Cilt: 37, Sayı: 2, ss. 421-428.

Iverson, R., \& Zatzick, C. (2011). The Effects Of Downsizing On Labor Productivity: The Value Of Showing Consideration For Employees' Morale And Welfare In High-Performance Work Systems. Human Resource Management, Cilt: 50, Sayı: 1, ss. 29-45.

Kağnıcıoğlu, D. (2001). İnsan Kaynakları Yönetimi Ve Değişen Endüstri iliş̧ileri. Anadolu Üniversitesi Sosyal Bilimler Dergisi, Cilt: 1, Sayı: 1, ss. 13-42.

Karcıoğlu, F., \& Öztürk, U. (2009). İşletmelerde Performans Değerleme İle İnsan Kaynakları Bilgi Sistemleri (iKBS) Arasındaki i̇lişkisi -i̇stanbul ilinde Bir Araştırma-. Atatürk Üniversitesi Sosyal Bilimler Enstitüsü Dergisi, Cilt: 13, Sayı: 1, ss. 343-366.

Keith, N., \& Frese, M. (2011). Enhancing firm performance and innovativeness through error management culture. Handbook of organizational culture and climate, Cilt: 9, ss. 137157.

Kutlu, S., \& Duran, C. (2010). Sanayi İşletmelerinde Toplam Kalite Yönetimi Ve ISO 9000 Uygulamalarının Performans Üzerine Etkisi. Dumlupınar Üniversitesi Sosyal Bilimler Dergisi, Cilt: 28, ss. 239-252.

Lawler, E. (1994). Total Quality Management And Employee Involvement: Are They Compatible? Academy Of Management Executive, Cilt: 8, Sayı: 1, ss. 68-76. 
Kuzutürk, B.; Kırkbeşoğlu, E. \& Tuzlukaya, Ş. (2021). İnsan Kaynakları Uygulamalarının Algılanan Örgütsel Performansa Etkisi. Fiscaoeconomia, 5(3), 918-935. Doi: 10.25295/fsecon.956217

Lowin, A. (1968). Participative Decision Making A Model Literature Critique, And Prescriptions For Research. Organizational Behaviour And Human Performance, Cilt: 3, Sayı: 1, ss. 59-68.

Murphy, K., \& Cleveland, J. (1995). Understanding Performance Appraisal: Social, Organizational, And Goal-Based Perspectives. USA: SAGE.

Park, R., Appelbaum, E., \& Kruse, D. (2010). Employee İnvolvement And Group İncentives İn Manufacturing Companies: A Multi-Level Analysis. Human Resource Management Journal, Cilt: 20, Sayı: 3, ss. 227-243.

Parnell, J.A. ve Crandall, W.R. (2001) Rethinking participative decision making: a refinement of the propensity for participative decision making (PPDM) scale, Personnel Review, Cilt: 30, Sayı: 5, ss.523-535.

Pfeffer, J. (1995). Competitive Advantage Through People: Unleashing The Power Of The Work Force. USA: Harvard Business Press.

Pfeffer, J., \& Veiga, J. (1999). Putting People First For Organizational Success. The Academy Of Management Executive, Cilt: 13, Sayı: 2, ss. 37-48

Pombo, G., \& Gomes, J. F. (2019). Employees' Perceptions and the Relationship Between Human Resource Management and Organizational Performance: A Conceptual View. Knowledge and Performance Management, Cilt: 3, Sayı: 1, ss. 46-63.

Porter, L., Lawler, E., \& Hackman, J. (1975). Behavior in Organizations. New York: Mcgraw-Hill Behavior In Organizations.

Poyraz, K., \& Kama, B. (2008). Algılanan İş Güvencesinin, İş Tatmini, Örgütsel Bağlılık Ve İşten Ayrılma Niyeti Üzerindeki Etkilerinin İncelenmesi. Süleyman Demirel Üniversitesi iktisadi Ve Idari Bilimler Fakültesi Dergisi, Cilt: 13, Sayı: 2, ss. 143-164.

Quinn, R., \& Spreitzer, G. (1997). The Road To Empowerment: Seven Questions Every Leader Should Consider. Organizational Dynamics, Cilt: 26, Sayı: 2, ss. 37-49.

Sabuncuoğlu, Z. (2000). Insan Kaynakları Yönetimi . Bursa: Ezgi Kitap Evi.

Scott, A., James, W., \& Dean, J. (1992). Integrated Manufacturing And Human Resource Management: A Human Capital Persfective. The Academy Of Management Journal, Cilt: 35, Sayı: 3, ss. 467-504.

Stewart, G., \& Brown, K. (2009). Human Resource Management. USA: Wiley Global Education.

Tailby, S., \& Winchester, D. (2005). Personnel Management In Transition. Managing Human Resources, Blackwell Publishing: USA.

Tortop, N., Aykaç, B., Yayman, H., \& Özer, A. (2006). İnsan Kaynakları Yönetimi, Nobel Yayınları.

Ugboro, I., \& Obeng, K. (2000). Top Management Leadership, Employee Empowerment, Job Satisfactions, And Customer Satisfaction in TQM Organizations: An Empirical Study. Journal Of Quality Management, Cilt: 5, ss. 247-272.

Uyargil, C. (2013). Performans Değerlemdirme. Insan Kaynakları. İstanbul: Beta. 
Kuzutürk, B.; Kırkbeşoğlu, E. \& Tuzlukaya, Ş. (2021). İnsan Kaynakları Uygulamalarının Algılanan Örgütsel Performansa Etkisi. Fiscaoeconomia, 5(3), 918-935. Doi: 10.25295/fsecon.956217

Varinli, İ., Yaraş, E., \& Başalp, A. (2009). Duygusal Zekânın Müşteri Odaklılık Ve Satış Performansı Üzerindeki Etkisini Belirlemeye Yönelik Bir Araştırma. Ege Akademik Bakış, Cilt: 9, Sayı: 1, ss. 113-130.

Wang, X., Bruning, N., \& Peng, S. (2007). Western High-Performance HR Practices In China: A Comparison Among Public-Owned, Private And Foreign-Invested Enterprises. The International Journal Of Human Resource Management, Cilt: 18, Sayı: 4, ss. 684-701.

Wood, S., \& De Menezes, L. (2011). High Involvement Management, High-Performance Work Systems And Well-Being. The International Journal Of Human Resource Management, Cilt: 22, Sayı: 7, ss. 1586-1610.

Wright, P., Gardner, T., \& Moynihan, L. (2003). The Impact Of HR Practices On The Performance Of Business Units. Human Resource Management Journal, Cilt: 13, Sayı: 3, ss. 21-36.

Youndt, M., Snell, S., Dean, J., \& Lepak, D. (1996). Human Resource Management, Manufacturing Strategy, And Firm Performance. Academy Of Management Journal, Cilt: 39, Sayı: 4, ss. 836-866.

Yüksel, Ö. (1997). Insan Kaynakları Yönetimi. Ankara: Volkan Matbaacılık.

Etik Beyanı: Bu çalışmanın tüm hazırlanma süreçlerinde etik kurallara uyulduğunu yazarlar beyan eder. Aksi bir durumun tespiti halinde Fiscaoeconomia Dergisinin hiçbir sorumluluğu olmayıp, tüm sorumluluk çalışmanın yazarlarına aittir.

Yazar Katkıları: Yazar katkısı açıklaması için örnek: Belkıs Kuzutürk çalışmada giriş, sonuç, kuramsal çerçeve ve ampirik literatür bölümlerinde ve veri toplama aşamalarında katkı sağlamıştır. Erdem Kırkbeşoğlu kuramsal çerçeve, metodoloji ve analiz aşamalarında katkı sağlamıştır. Şule Tuzlukaya, bulgular ve sonuç kısmında katkı sağlamıştır. 1. yazarın katkı oranı: \%50, 2. yazarın katkı oranı: \%30, 3. Yazarın katkı oranı \%20'dir.

Çıkar Beyanı: Yazarlar arasında çıkar çatışması yoktur.

Ethics Statement: The authors declare that ethical rules are followed in all preparation processes of this study. In case of detection of a contrary situation, Fiscaoeconomia has no responsibility and all responsibility belongs to the authors of the study.

Author Contributions: Belkıs Kuzutürk contributed to the study in Introduction, Conclusion, Theoretical Framework and Empirical Literature sections and data collection stages. Erdem Kırkbeşoğlu contributed to the study in the Theoretical Framework, Methodology and analysis sections. Şule Tuzlukaya contributed to the study in the findings and conclusion sections. 1st author's contribution rate: $50 \%$, 2 nd author's contribution rate: $30 \%$, 3th author's contribution rate: $20 \%$.

Conflict of Interest: There is no conflict of interest between the authors. 
Kuzutürk, B.; Kırkbeşoğlu, E. \& Tuzlukaya, Ş. (2021). İnsan Kaynakları Uygulamalarının Algılanan

Örgütsel Performansa Etkisi. Fiscaoeconomia, 5(3), 918-935. Doi: 10.25295/fsecon.956217

The Impact of Human Resources Practices on Perceived Organizational Performance

\section{Belkıs KUZUTÜRK, Erdem KIRKBEŞOĞLU, Şule TUZLUKAYA}

\section{Extended Abstract}

In the past, human resources management as a field of study focuses only on administration tasks in contrast to the present. Today HRM is considered vital in terms of determining business strategies. Therefore, human resources applications are considered as necessary tools that organizations can use to gain a strategic advantage over their competitors (Chiang et al., 2017).

Human resources applications have certain standards although they vary in terms of organizational types. Following certain standards is also important when one focuses on the employee perception of such practices (Hofman \& Meijerink, 2015). According to Varinli et al., (2009) there is an important relationship between the perceived performance and such variables as market efficiency and customer satisfaction. Besides, employees generally focus on success and high performance in the long term. Many human resources practices can be effective on the employee perception. Mainly in the literature, practices such as training and encouragement are perceived positively by the employees (Pombo \& Gomes, 2019). Also, perception related to performance is one of the variables that may lead to the relationship between the organization and the employee. The human resources applications' stages include evaluating the activities of the organization as a whole and advancing each of the applications following the process. These practices are considered selective recruitment, training, remuneration, job security, empowerment, employee participation, symbolic equality, and performance appraisal.

Selective recruitment or selection is one of the most important items. Selection is a kind of activity finding out the individuals that have the knowledge, skills, and abilities that the organization needs. During the process, generally, the cost of the recruitment process is vital. Therefore, the allocation of time and effort should be managed. If the process takes longer then required, there will be a loss of production (Scott et al., 1992). It is not only related to the selection process. Organizations should choose the employee among the candidates who are close to the organizational culture. This will also be effective in ensuring sustainable organizational performance.

Education is another important item. Contribution to values such as human, intellectual, and social capital with education provides an incomparable competitive advantage for organizations as it develops a labor force that is difficult to imitate (Cheng \& Hampson, 2008). Developing the knowledge skills and abilities of the employees by recruiting the right employee for the right job and applying various training programs increases the employee's commitment to the job and the organization, ensures their motivation, and ensures that the organization's human capital is at the highest level, maintaining its competitive advantage and increasing the quality of working life (Bayat, 2008 ).

Organizations can adopt various rewarding policies to retain human resources that create value or to provide long-term employment. Remuneration is realized by rewarding the workforce individually or as a group for the values that participate in the organization in certain ways and rates (Pfeffer, 1995). Attracting, retaining, and motivating the workforce can 
Kuzutürk, B.; Kırkbeşoğlu, E. \& Tuzlukaya, Ş. (2021). İnsan Kaynakları Uygulamalarının Algılanan

Örgütsel Performansa Etkisi. Fiscaoeconomia, 5(3), 918-935. Doi: 10.25295/fsecon.956217

be achieved with an attractive reward system (Yüksel, 1997). When organizations implement a proper system, rewarding shows that employees perform at a higher level and are motivated to work (Huselid, 1995).

The decrease in job security reduces job satisfaction and organizational commitment (Poyraz \& Kama, 2008). Therefore, when employees are guaranteed long-term relationship with the organization, the work efficiency of the employees' increases, and people who are compatible with the organizational culture and who are affiliated with the organization stay in the organization (Beer \& Nathaniel, 2015). In this way, they will be more willing in terms of education, development, and work. Thus work efficiency will be increased (Beer et al., 2009).

The more information employees have about the process of the work, the more they can contribute to the development of the business. Especially for employees, technical knowledge, responsibility, and empowerment are required (Bailey et al., 2001). Empowerment studies have an important contribution to increasing the commitment to the organization with the responsibility, authority, or other non-material rewarding processes given to the employee (Beer \& Nathaniel, 2015). Employees want to feel that they are valuable from their organizations with moral support as well as financial rewards and that they make important decisions in the organization by giving authority and responsibility (Stewart \& Brown, 2009). Therefore, employees who perceived that they are important, and find the job meaningful, can participate in all the processes (Gümüşlüoğlu \& Karakitapoğlu, 2010).

Organizations seeking competitive advantage should take joint decisions with their employees and involve them in the process (Iverson \& Zatzick, 2011). Organizational structures that support employee participation and strengthen their employees will be helpful to achieve more effective performance (Huselid, 1995). When employees have a personal role in decision-making processes and problem-solving stages of the organization, that will also increase job satisfaction (Wood \& De Menezes, 2011). The transparency and sincerity brought by participatory decision-making between the employee and the management will ensure that the performance of the company is positively increased by applying the ideas and decisions of the management and employees (Kutlu \& Duran, 2010).

The organization needs to evaluate the individual for whom it provides a competitive advantage because the sum of individual performances might determine the overall performance of the organization (Uyargil, 2013). Thus the results of performance appraisal are used in human resources planning and human resources management decisions. As a result of performance evaluation, human resources management is provided with data on what employees should do to show effective behaviors and attitudes on the way to the goals of the organization. Increasing employee performance on an individual basis plays a major role in achieving the strategic goals of the organization.

The primary aim of this study is to investigate the impact of human resources practices on perceived organizational performance. In this study, a quantitative research approach is carried out and the survey design is applied for data collection. SPSS 24 package proram was used to analyze the data in this study.

Findings show that recruitment, participatory decision making, performance evaluation, rewarding, and empowerment actions from human resources practices have a significant 


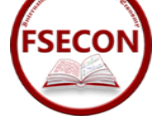

Kuzutürk, B.; Kırkbeşoğlu, E. \& Tuzlukaya, Ş. (2021). İnsan Kaynakları Uygulamalarının Algılanan Örgütsel Performansa Etkisi. Fiscaoeconomia, 5(3), 918-935. Doi: 10.25295/fsecon.956217

effect on organizational performance. It was concluded that on the job training and job security variables proved to be effective in international literature do not provide any significant effect. Especially in contexts where economic and social crises are increasing employees are likely to feel insecure, even though businesses offer high job security. Therefore, while job security has a meaningful explanatory effect on performance in contexts where uncertainty is low; In the context of high uncertainty, such as Turkey that may be difficult to capture this interaction. 